\title{
Study on the Information Visualization Technology and Application Wu Lijie ${ }^{1}$, Luo Bin ${ }^{1}$, Ye Ziwei ${ }^{2}$, An Zhiyuan ${ }^{1}$, Liu Bo ${ }^{1}$, Wang Chunying ${ }^{1}$ \\ ${ }^{1}$ Information \& Telecommunication Co. of State Grid Henan Electric Power Company, Zhengzhou, 450052, China
}

${ }^{2}$ Informational Engineering Department of Zhengzhou University, Zhengzhou 450001 China

Keywords: information visualization; electric power communication; integrated monitoring

\begin{abstract}
With the expansion of power system, power system visualization demand is also increasing, if present in the form of regular grid information, operators can't take care of, let alone. In this paper, the visualization technology applied in electric power communication, so easy to use personnel in a timely manner to understand network status, provide the basis for electric power communication safety in production.
\end{abstract}

\section{Introduction}

Information visualization is using the computer support, interaction, visual representation of abstract data, to enhance people's perception of the nonphysical abstract information. This paper introduces the information visualization techniques including GIS, GPS and other technological developments, and secondly, analyses the feasibility and necessity of information visualization in power system[1]. At last, it analyses the architecture of information visualization system in power system and introduces information visualization in the practical application of power system with a simple description.

\section{Visualization Technology}

The Visualization is the technology that late 1980s with the development of computer technology. Is to put some complex text and data into intuitive graphics and images, help people to understand the meaning of data, or process, so that the nature of the physical process, and it is a supplement to the data or words and ascend. According to the data dimension, the time characteristic and the structure features, visual classification table as follows:(As shown in table 1)

According to the principle of the visualization can be divided into different standard 2D/3D technology, based on the geometric projection technology, technology, based on the icon for pixels based on the level of technology, technology, based on the graphic technology, based on the geographic information technology, virtual reality technology, hybrid technology, etc.

One based on geographic information visualization method, divided into two ways, one is based on geographic information as the background, overlay display visual information; Another is the use of geographical elements display information, as shown in the figure below [2].

Virtual reality is a new technology, it is based on computer technology as the core, the integrated use of all the latest technology, fusion visual, hearing, touch, as one of the imitation of real three-dimensional space technology. Through virtual reality system, users with certain equipment (low display, data glove, etc.), with its natural skills to interact with it, immersive experience and feelings, as shown in figure 1.

\section{Electric Power Communication Visualization Display Technology Research and Application}

In terms of power transmission and transformation, realize visualization based on GIS, including transmission line, substation, tower layout of environmental information (including the lightning, dirty area, natural disasters), substation 3D layout, equipment 3D figure. Implements the leadership cockpit in with electricity, based on GIS, area wiring diagram and power outlets, meter reading path diagram, expanding new aided design, the optimal space location, load migration auxiliary 
decision-making[3]. In scheduling management to achieve the voltage, current, power, and power load, active and reactive power visual display, real-time monitoring the application of dynamic trend graph (active, reactive power, power transfer distribution factor PTDF); Achieved expected accident analysis (CA), equipment status, contour, load density, short circuit current and voltage transformer load reactive power, generator active, station reactive power reserve monitoring visual display. In cross link applications, including emergency command, the whole life of assets and power transmission and transformation equipment condition monitoring system used in all kinds of other means of visual display, raise the level of system to use. In information operations applications, the entire network monitoring, including monitoring, map the network province IMS system implementation status display, the network IMS system running status display, the network province important alarm real-time display, the network cities regional view shows statistical chart shows, regional operations. Topology monitoring, IMS operations on important to dynamic display data and statistics. Users can monitor its wide-area network topology structure, can also were unfolding down the net of the provinces, cities and monitor network topology structure. Implement the business monitor display[4]. From the perspective of a business system for real-time monitoring operation of business systems. Business monitoring list of show model including the main indicators monitoring, business district distribution topology monitoring, business monitoring, etc. In communication network management has realized the computer room floor plan to show. Through computer room floor plan can see inside the room layout, equipment information such as the placement, the computer room environment situation, implement the topology management and transmission cable resources management based on GIS.

Table 1 Visualization classification table

\begin{tabular}{|l|l|}
\hline \multicolumn{1}{|c|}{ Style } & \multicolumn{1}{|c|}{ Instruction } \\
\hline $\begin{array}{l}\text { One-dimensional information } \\
\text { visualization }\end{array}$ & $\begin{array}{l}\text { Simple linear information, such as text, program source } \\
\text { code. }\end{array}$ \\
\hline $\begin{array}{l}\text { Two-dimensional information } \\
\text { visualization }\end{array}$ & $\begin{array}{l}\text { There are two main characteristic of spatial attribute } \\
\text { information. For example, said the width and height size } \\
\text { object, Use the position of the object in the X, Y axis spatial } \\
\text { orientation. The most common form of 2 d information } \\
\text { visualization is the GIS. }\end{array}$ \\
\hline $\begin{array}{l}\text { Three-dimensional } \\
\text { information visualization }\end{array}$ & $\begin{array}{l}\text { With the introduction of the concept of volume, used in } \\
\text { many aspects, especially the construction and medical fields. }\end{array}$ \\
\hline $\begin{array}{l}\text { Multi-dimensional information } \\
\text { visualization }\end{array}$ & $\begin{array}{l}\text { Described above 3 kinds of attribute information of the } \\
\text { object. }\end{array}$ \\
\hline $\begin{array}{l}\text { Time series information } \\
\text { visualization }\end{array}$ & $\begin{array}{l}\text { Have the time attribute information referred to as a time } \\
\text { series. With a time line to line up data to the user at a glance } \\
\text { can continue happens to see the before and after the event, } \\
\text { and which is associated with other events. }\end{array}$ \\
\hline $\begin{array}{l}\text { Level } \\
\text { visualization }\end{array}$ & $\begin{array}{l}\text { Abstract information is one of the most common relationship } \\
\text { between hierarchical relationships, such as disk directory } \\
\text { structure, document management, books classification, and } \\
\text { so on. }\end{array}$ \\
\hline $\begin{array}{l}\text { Netwe hierarchical structure of the network information has no } \\
\text { visualization }\end{array}$ & $\begin{array}{l}\text { fixed, there may be multiple paths between two nodes, the } \\
\text { nodes and the relationship between the nodes and the } \\
\text { number of attributes is variable. }\end{array}$ \\
\hline
\end{tabular}




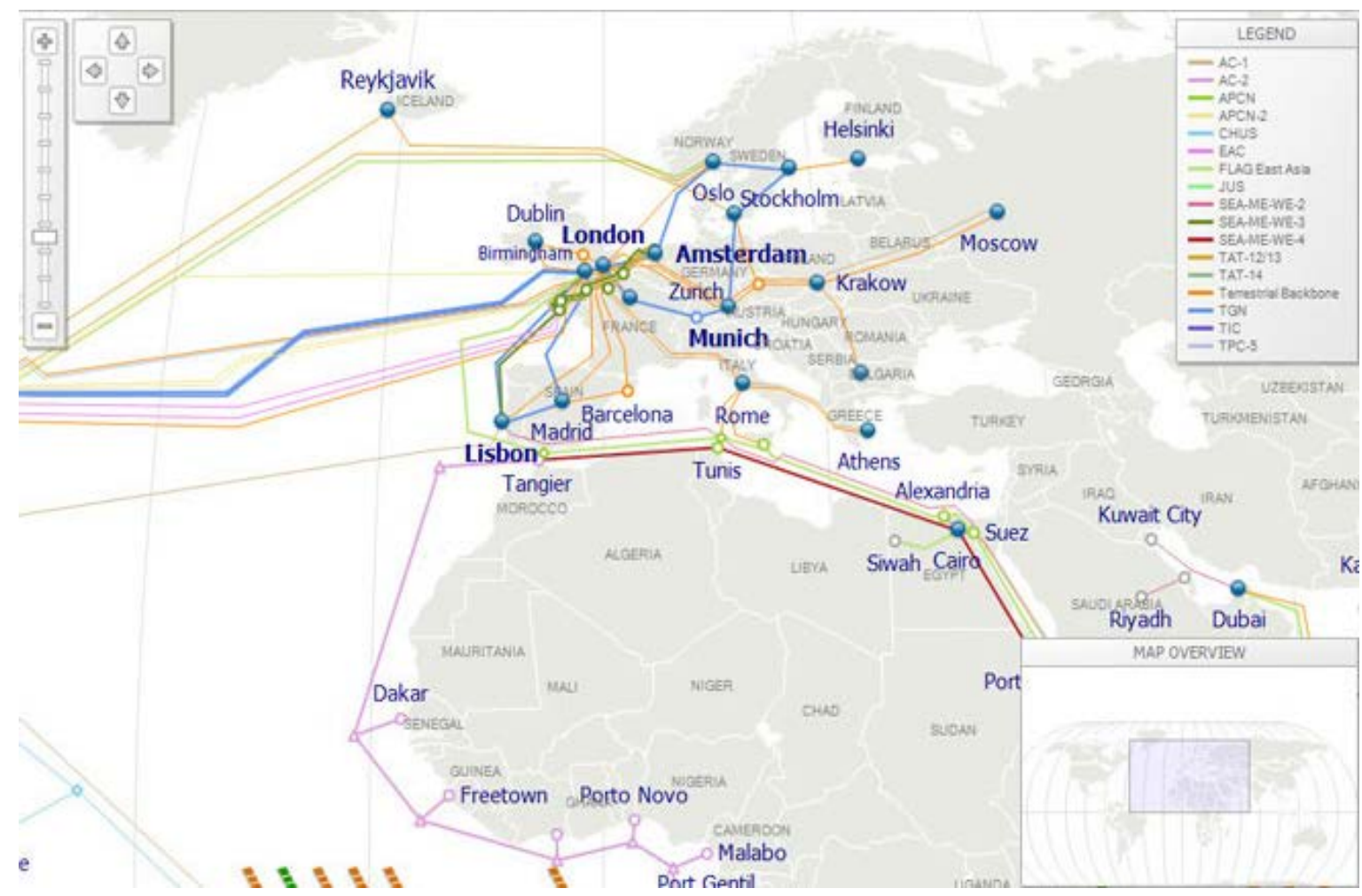

Fig. 1 The visual figure of GIS

\section{Conclusion}

In study of visual representation model, developed for a unified figure standard equipment, based on the single line diagram and the transmission and distribution management of GIS application effect is good, has the rich visualization research and engineering experience.

\section{References}

[1]Song Xiao-xu. Intelligent scheduling of big data visualization technology research [D]. North China electric power university (Beijing), 2015.

[2]Zheng Jia-jia. Big data information display interface interaction design research [D]. Southeast university, 2015.

[3]Yang Yun-mei. Based on the fast data visualization framework of sampling[D]. Huazhong university of science and technology, 2015.

[4]Wang Fang, Chen Dao-he. Big data technology in the college teaching reform[J]. Computer knowledge and technology, 2015,(9) . 